\title{
El Comercio Justo, soñando con los pies en la tierra
}

John Forero Lozano*

\begin{abstract}
Resumen
El Comercio Justo se presenta como una alternativa de desarrollo sostenible que brinda a los pequeños productores y a los campesinos la oportunidad de negociar con una diferente perspectiva. El fin es generar beneficios justos de acuerdo al trabajo realizado para alcanzar una mejoría en el sistema de transacciones mercantiles; propone un sistema que evita la explotación de los trabajadores del campo, proponiendo el desarrollo de un mercado basado principalmente en la ética y el desarrollo de una conciencia humana más solidaria y justa, principalmente, con los pequeños productores y campesinos del los países del sur. Plantea un reto para encontrar un modelo de desarrollo sustentable como una opción viable para la consecución del bienestar de la población que trabaja en el agro. Esta propuesta no puede ser considerada como un recetario mágico que garantice el éxito, sino que parte de de un profundo cambio en la conciencia de cada productor y del conglomerado de poblaciones campesinas. El sistema promueve la organización y el aprendizaje que permita mantener los mercados con productos de alta calidad y estándares internacionales.
\end{abstract}

\section{Palabras clave}

Comercio Justo - familias campesinas - pequeños productores - productores campesinos - explotación del trabajo de campo - desarrollo sustentable

\begin{abstract}
Fair trade is presented as a sustainable alternative that provides smallproducers and farmers the opportunity to negotiate with a different perspective. The aim is to produce fair benefits according to the effort the achieve an improvement done in the trade system, proposing a system that prevents the exploitation of farm workers, proposing development of a market based on ethics and the development of a human consciousness solidarity and justice, primarily with small farmers and peasants of the South. Presents a challenge to find a model of sustainable development as a viable option for achieving the welfare of the agriculture workers. This proposal cannot be regarded as a magic recipe that will guarantee success, but part of a profound change in consciousness of each producer of rural populations. The system promotes the learning to keep markets with high quality products and standards.
\end{abstract}

\section{Key words}

Fair trade - family farmers - small producers - peasant producers - exploitation of fieldwork sustainable development

Forma sugerida de citar: Lozano Forero, John. 2011. El Comercio Justo, soñando con los pies en la tierra. Retos 1. Enero/Junio. Pp. 53-63.

* Consultor en temas de desarrollo.yafolo@hotmail.com.

Retos I(I): 20II.

(c) 2011, Universidad Politécnica Salesiana del Ecuador 
Nací en un hogar campesino y mi niñez la pasé entre ellos. He disfrutado de la naturaleza, del viento, del agua; desde muy chico aprendí de sus saberes, sus cuentos, sus historias, sus canciones, su comida, sus alegrías y tristezas, sus campos y cultivos, pero sobre todo de su compañía. Hoy vivo en la ciudad y guardo el sentir del campo y la memoria del conocimiento ancestral. Y me pregunto todavía:

\section{¿Por qué las familias campesinas,} siendo tan trabajadoras, siguen tan empobrecidas? ¿Por qué seguimos siendo testigos de su explotación diaria?

Quisiera creer que son cosas del pasado, las mismas que vivió el padre Graziano Mazón hace más de 25 años en Muisne y que le llevaron a fundar Maquita Cushunchic Comercializando como Hermanos (MCCH), o Wilser Mendoza en Vinces, cuando era víctima de los comerciantes o intermediarios, de sus básculas manipuladas y los descuentos desmedidos por la humedad del cacao. Pero no, las explotaciones que sufren los campesinos siguen siendo cosas del presente, de esta segunda década del siglo XXI.

Para evitar esta explotación, se ha generalizado en los últimos veinte años la tendencia a desarrollar una conciencia más humana, solidaria y justa en grandes sectores, tanto de consumidores de países del Norte, principalmente de Europa, como de algunos productores, principalmente campesinos, de los países del Sur, lo que ha permitido un mayor crecimiento del Comercio Justo, que sembró sus primeras semillas en Estados Unidos en los años cuarenta, en el marco del Comité Central Menonita, posteriormente conocido como Ten Thousand Villages (Diez Mil Aldeas), que comerciaba con comunidades pobres del Sur, con el objeto de generar fuentes de trabajo e ingresos. Y luego en Europa, en la década del cincuenta, cuando Oxfam del Reino Unido comerciaba a una escala pequeña con refugiados chinos (López, 2005: 15).

Se conoce a esta tendencia como Comercio Justo desde los primeros años de la década del sesenta, principalmente en los países nórdicos, donde unos pocos consumidores de productos importados de países del llamado Tercer Mundo notaron la enorme diferencia entre el alto precio que ellos pagaban en sus mercados por el café, cacao, té, azúcar, banano, artesanías, entre otros, y el bajo precio que les pagaban a los campesinos que los cultivaban. "Mientras los agricultores venden el café asumiendo fuertes pérdidas, los cafés de marca se venden al público, generando importantes beneficios" (Oxfam, El café de Comercio Justo: 2). En esta misma década, de acuerdo a EUROPEAN FAIR TRADE ASSOCIATION (2003): "Oxfam, Reino Unido, creó la primera organización de Comercio Justo, mientras iniciativas similares nacían en Holanda, donde se formó la primera importadora, Fair Trade Organisation (Organización de Comercio Justo)" (López, 2005: 16). 
Según los manifiestos hechos durante las huelgas organizadas en ese entonces por varias organizaciones campesinas de los países del Sur, los precios impuestos por los intermediarios de los países del Norte les obligaban a emplear a sus hijos en los cultivos en lugar de enviarlos a la escuela, a recibir bajos salarios e incluso a no remunerar el trabajo de sus mujeres. Indicaban también que, en muchas ocasiones, este maltrato y la mala paga resultaban en un trabajo a pérdida. Por estas razones, los campesinos exigían un precio justo por sus productos, que les permitiera al menos cubrir sus necesidades básicas.

Al respecto Rufino Herrera, campesino dominicano y pequeño productor de café, afirma:

Los precios del café en los mercados internacionales están sujetos a la especulación; por ello, cíclicamente se hunden y arrastran con ellos a miles de familias campesinas. Entre los años 2000 y 2001 en República Dominicana no se recogió el café de las matas, el coste era superior al precio que se ofrecía por las cosechas. El mercado nos daba 23 dólares por quintal de café, mientras los precios de café de Comercio Justo se mantuvieron en 124 dólares el quintal. La crisis provocó que algunas plantaciones fueran sustituidas por cultivos de ciclo corto, pero otras fueron abandonadas y sus propietarios emigraron a las ciudades. La parte positiva es que unió a muchos productores y ahora el $25 \%$ de los pequeños cafetaleros formamos parte de alguna asociación. Hoy, que los precios están altos, el Comercio Justo sigue pagando 35\% más por las cosechas (Niell, 2008).

Infortunadamente, la experiencia de los caficultores dominicanos no es ajena a la de los caficultores ecuatorianos, en el Gráfico 1 vemos la diferencia entre el precio del café en el mercado tradicional y el del Comercio Justo.

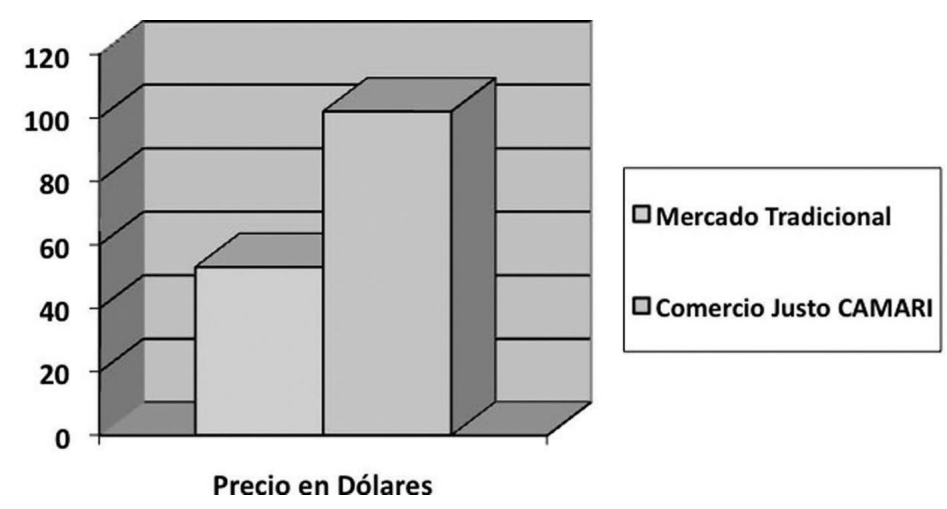

Gráfico 1. Diferencia en el precio de compra de café en Ecuador Fuente: Mauricio López (2005); elaborado por el autor

Retos I(I): 2011 .

(C) 201 I, Universidad Politécnica Salesiana del Ecuador 
Más tarde, primero en Holanda y luego en Bélgica, Alemania, Suiza, Austria, Francia, Suecia y Gran Bretaña, las voces de estos pequeños campesinos del Sur tuvieron eco. En estos países se abrieron las primeras tiendas de Comercio Justo, en las que les garantizaban un precio justo por sus productos, que intentaba representar el equivalente al tiempo y trabajo invertidos por el campesino, su familia y sus trabajadores en producirlos.

En la actualidad, solo en Europa existen más de 5.000 tiendas y unos 45.000 puntos de venta de productos de Fair Trade o Comercio Justo. Esta red de tiendas solidarias tiene un contacto directo y permanente con más de 800 organizaciones de pequeños productores de países del Sur, en donde existen más de cinco millones de personas que se benefician de esta forma alternativa de comercio.

Desde finales de la década del noventa, de la mano de ONG nacionales e internacionales, cooperación internacional, organizaciones bilaterales y multilaterales, el Comercio Justo ha ido ganando su espacio en Ecuador. Cada vez son más las organizaciones de pequeños productores ecuatorianos que alcanzan en esta forma de comercialización mejores beneficios que en el comercio tradicional, y por ello cada día se vinculan en mayor número a ella.

Retos I(I): 201I.

(C) 201 I, Universidad Politécnica Salesiana del Ecuador
Sin embargo, en Ecuador y en otros países, no todas las experiencias de Comercio Justo han sido exitosas. Muchas de estas iniciativas han muerto en el intento, y no se ha hecho un análisis serio sobre sus causas.

Esto fue el origen de la investigación "Cómo lograr que el Comercio Justo sea una opción sostenible de acceso a mercados para organizaciones de pequeños productores", una de cuyas preguntas iniciales fue:

\section{¿Cuáles son los beneficios, ventajas y oportunidades que tiene el Comercio Justo para los pequeños productores y campesinos ecuatorianos?}

$\mathrm{Su}$ respuesta se puede deducir de la información presentada en los Cuadros 1 y 2 . Adicionalmente, es conveniente recordar las palabras del campesino dominicano Rufino Herrera:

El Comercio Justo no es solo mejores precios para los campesinos, es una inversión para toda la comunidad y un fortalecimiento de las organizaciones productoras que les permite sentarse frente a la administración no con el traje de campesinos sino con el de empresa. Estamos distribuyendo los beneficios de este comercio de manera equitativa entre los socios de las cooperativas y contribuyendo a mejorar nuestras comunidades: nosotros construimos las escuelitas y le pedimos al Estado que pague a los maestros. Negociamos cara a cara con instituciones 
como la universidad y hemos conseguido becas para nuestros hijos e hijas, que hoy son gerentes, contables, administradores de empresas y agrónomos. Yo solo llegué a cuarto de primaria pero, gracias al Comercio Justo, mis hijos son administradores de empresa y trabajan con nosotros en Federares (Niell, 2008).

De la misma manera, según la Organización Internacional de Etiquetado de Comercio Justo, red con sede en Bonn, Alemania: "entre 2000 y 2007, el Comercio Justo ha experimentado un crecimiento sostenido de más del 20\% anual en toda Europa. En países como Finlandia, Suecia, Francia y Austria ese crecimiento superó el 60\% anual en 2004-2005" (Cronin, 2007). Gráfico 2.

Este crecimiento en el mercado va de la mano de medidas y políticas públicas adoptadas por algunas ciudades o países a favor de esta nueva forma de comercio como la implementada en algunas escuelas de Roma, donde se dan alimentos orgánicos y de Comercio Justo a niños y niñas en las escuelas desde 1999. Otro ejemplo de este tipo de políticas ha sido la experiencia de la Oficina de Correos Nacionales de Francia que, desde el 2007, fabrica todas las camisas de los uniformes de sus carteros con algodón 100\% de Comercio Justo producido en la India (Cronin, 2007). En la misma línea, desde 2008, todo el café que se consume al interior del recinto ferial de Expo Zaragoza tiene el sello de Comercio Justo. Esta corriente, vinculada a la administración pública, ha avanzado de tal manera que desde el año 2000 aparecieron las primeras Ciudades Justas, y en los últimos años se habla de colegios y universidades por el Comercio Justo.

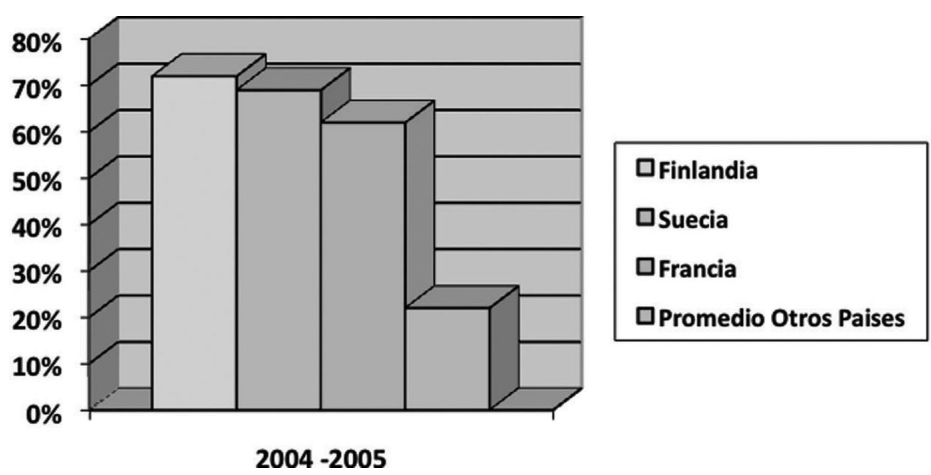

Gráfico 2. Crecimiento del mercado de Comercio Justo en algunos países de Europa. Fuente: David Cronin (2007). Elaborado por el autor 
Una ciudad justa o ciudad por el Comercio Justo es un modelo de ciudad que fomenta la inserción de los criterios de Comercio Justo en el consumo y las compras de las administraciones, comercios, empresas y otras instituciones públicas y privadas. En Europa, el programa tiene el apoyo de la Comisión Europea a través del programa Ciudades Europeas por el Comercio Justo (Fair Trade Towns in Europe). Actualmente hay más de 300 ciudades justas en toda Europa, entre las que se encuentran Roma, Bruselas, Oxford, Córdoba, Madrid, Sevilla, Zaragoza, Málaga, Granada, Cádiz, Bilbao, Albacete, Dublín, Belfast, entre otras. (^http://es.wikipedia. org/wiki/Ciudad_justas).

En la misma línea, estudios de OXFAM muestran que, aun cuando enfrenta dificultades, el Comercio Justo es una alternativa mejor que la del comercio tradicional para que los pequeños productores mejoren su calidad de vida. Otros estudios muestran que, en igualdad de condiciones, los pequeños productores que han incursionado en el Comercio Justo tienen mayores beneficios que los productores que incursionan en el comercio tradicional.

Todo lo anterior nos demuestra que sí ofrece beneficios, ventajas y oportunidades para las familias campesinas y de pequeños productores ecuatorianos. Con esta respuesta surge otra pregunta:

Retos I(I): 2011 .

(C) 201 I, Universidad Politécnica Salesiana del Ecuador

\section{En el marco de un desarrollo sustentable, ¿es el Comercio Justo una alternativa válida y real para la reducción de la pobreza en Ecuador?}

Nuestro país desde la Colonia y luego como República se vivuló al comercio internacional como productor primario de productos específicos. Primero fue el caucho, luego el cacao, seguido del banano, posteriormente el petróleo, las flores, los camarones y últimamente como proveedor de mano de obra, a través de los migrantes. Es decir, Ecuador ha estado, comercialmente hablando, vinculado con el mundo desde el lado más débil de la cuerda.

En esta línea, es oportuno citar la investigación sobre la pobreza Cambiar las Reglas, realizada por OXFAM: "generalmente, las políticas, las instituciones y las normas que gobiernan el comercio internacional a escala global tienen una orientación intrínsecamente contraria a los intereses de los pobres. Pese a que las teorías convencionales sobre comercio predicen que los pobres se beneficiarán de un mayor comercio gracias a la creación de empleo en los sectores que requieren mucha mano de obra, la realidad indica que la desigualdad en las relaciones comerciales está limitando la lucha contra la pobreza, reforzando las desigualdades sociales y marginando a los países y a las personas más pobres" (OXFAM, 2002: 64). En efecto, al carecer de los 
recursos y activos necesarios para poder beneficiarse de las oportunidades que ofrece el comercio, esta investigación de OXFAM muestra que en los países más pobres e incluso en las franjas más pobres de países de ingresos medios, muchos de aquellos que han accedido a un empleo corren el riesgo de quedarse con lo mínimo necesario para vivir (OXFAM, 2002: 64), y/o de acceder únicamente a empleos con niveles extremadamente bajos de salarios. Por otro lado, la expansión del comercio ha estado vinculada a la intensificación de las desigualdades entre los sexos, y a una exposición cada vez mayor a los riesgos laborales y problemas de salud. Finalmente, se indica que el crecimiento de las exportaciones también puede dañar el entorno natural, marginando con ello aún más a los pobres (OXFAM, 2002: 65). En este contexto, es natural que los productores más pobres intenten incursionar en formas más justas de comercio, aunque muchas veces lo hagan sin un conocimiento real de lo que es el Comercio Justo, las redes de soporte que existen ni los valores que promueve.

Los dos párrafos anteriores evidencian que el comercio tradicional no ha sido el camino más indicado para los pequeños productores, ni para la reducción de la pobreza en Ecuador. Si el comercio tradicional no ha sido el camino, resulta lógico tomar otro. En este sentido, es importante tener en cuenta que el país y en especial el sector rural han cambiado considerablemente en las últimas cuatro décadas, en parte gracias a la modernización que trajo el boom petrolero, hasta llegar al punto en el que algunos autores hablan de "la nueva ruralidad" que vive el Ecuador, que ha dejado de ser un país campesino, la población rural cambió del 72\% en 1950 al 38\% en 2001 (Vásquez, 2008: 157). Cambiaron también el trabajo rural y los ingresos del sector rural. Y lo que es peor, ya en 1990 cerca del $60 \%$ de las familias rurales poseía menos de una hectárea de tierra (Martínez, 2007: 153), todos los estudios muestran que este porcentaje aumentó en las dos últimas décadas; es decir, tenemos campesinos sin tierra.

En el contexto de una 'nueva ruralidad', de aumento de la pobreza y de escasas oportunidades para los sectores marginados, es oportuno empezar a ver qué alternativas tenemos y aprovechar las nuevas oportunidades. Esto es precisamente lo que ha sucedido con algunas experiencias de Comercio Justo que son paradigmáticas en Ecuador ya sea por su larga trayectoria, su constante crecimiento o por el mejoramiento cuantitativo de la calidad de vida de las familias que hacen parte de ellas. Las más importantes son las impulsadas por el Grupo Social FEPP, la Fundación Consorcio de Queserías Rurales 
Comunitarias del Ecuador Salinerito (Funconquerucom), El Camari, Fundación Sinchi Sacha y MCCH. Además de estas experiencias 'históricas' existen muchas iniciativas más pequeñas que están asociadas generalmente con la agroecología, las artesanías y el turismo ecológico y comunitario, que además de ir por el mismo camino van alcanzado resultados similares.

Pese a lo difícil del contexto, estas experiencias nos han demostrado que el Comercio Justo es una alternativa válida y real para la reducción de la pobreza en Ecuador.

Si éste ofrece beneficios, ventajas y oportunidades para las familias campesinas y de pequeños productores ecuatorianos y, además, constituye una alternativa válida y real para la reducción de la pobreza en Ecuador, entonces:

\section{¿Por qué las familias campesi- nas y de pequeños producto- res no hacen Comercio Justo y gozan de esos beneficios, ventajas, oportunidades?}

$\mathrm{Al}$ investigar encontramos que aunque el Comercio Justo ha experimentado un fuerte crecimiento en los últimos años en Ecuador, aquellas familias campesinas y de pequeños productores que conocen o están enterados del tema y de sus beneficios todavía representan un porcentaje mínimo. Además, hay factores que facilitan o dificultan el alcance de estos buenos resultados en la práctica del Comercio Justo y desafortunadamente no son pocas las experiencias que fracasan en el intento.

Si no es tan fácil hacer Comercio Justo y además existen factores que facilitan o dificultan alcanzar los buenos resultados, entonces:

\section{¿Cómo lograr que el Comercio Justo sea una opción válida, real y sostenible para mejo- rar la calidad de vida de las familias campesinas y de los pequeños productores?}

Creemos que es oportuno atreverse a mirar un punto nuevo en el horizonte: el inicio de nuevas experiencias de Comercio Justo, y que éstas deben abrirse camino sin las herramientas de siempre: aprendizaje y adaptación a una forma diferente de hacer economía. Entre las experiencias nuevas y las llamadas 'históricas' deben empedrar el camino: sentar unas bases sólidas para que este sea duradero. Incursionar en el Comercio Justo requiere una adaptación de los individuos y de la organización a una forma de relaciones económicas y sociales no tradicionales, que se alinien con sus principios. Esto requiere cambios culturales profundos en las dimensiones organizativa, política, económica, tecnológica, humana y ambiental. 
Asimismo, creemos que este camino del Comercio Justo, cada vez más transitado por diversas experiencias exitosas, debe llevar a espacios en los que se discuta el modelo de desarrollo sustentable que le permita a Ecuador aprovechar realmente las ventajas comparativas y competitivas, y sobre todo las características propias del entorno y la cultura ecuatorianas. Entonces, el reto como país debería ser encontrar un modelo de desarrollo sustentable a lo ecuatoriano.

Como punto de partida para las nuevas experiencias de Comercio Justo y para aquellas que ya llevan un tiempo en este camino y se siguen preguntando: ¿Cómo lograr que el Comercio Justo sea una opción válida, real y sostenible para el aumento de la calidad de vida de las familias campesinas y de los pequeños productores?, hacemos a través de esta investigación una Propuesta de Guía Práctica para el Análisis de Experiencias de Comercio Justo[1]", que, en ningún caso, puede ser considerada como un recetario mágico que garantice el éxito, sino que parte del convencimiento profundo de que cada productor y organización tienen su propia dinámica y entorno. Incluso se puede decir que una organización que tome los aprendizajes de las experiencias descritas en la Propuesta de Guía como una receta aplicable en todos los casos, estará destinada hacia el fracaso. Si bien las preguntas generadoras pueden salir de las experiencias de otros, de seguro las respuestas correctas solo podrán surgir de la capacidad de autodiagnóstico, las particularidades, la creatividad y los sueños de cada organización.

La intención de esta Propuesta de Guía es la de generar un material de análisis de cada entorno con base en preguntas generadoras que han sido útiles para entender las condiciones de éxito y de fracaso de otras experiencias similares.

De esta forma, este material permite no solo recuperar las lecciones aprendidas de algunas experiencias no tan exitosas de Comercio Justo sino, además, convertirlas en algo útil para que las familias campesinas y de pequeños productores, investigadores, estudiantes, técnicos, miembros de organizaciones y consumidores sensibles se pregunten, analicen, discutan, investiguen y tomen las decisiones pertinentes.

Asimismo, esta Propuesta permite abordarlo desde varios ángulos, siempre de acuerdo a la realidad de cada experiencia, y quiere convertirse en una herramienta para que las organizaciones aprendan de su propia experiencia y, mediante la reflexión y el análisis, obtengan la información necesaria para tomar las decisiones que hagan posible alcanzar de mejor forma sus beneficios y ventajas. Y, así poder soñar un Comercio Justo, pero con los pies en la tierra. 


\section{Cuadro 1. Principios fundamentales del Comercio Justo}

- Alcanzar condiciones de vida dignas para productores, trabajadores y sus familias. Cada persona debe vivir dignamente de su trabajo, para ello hay que garantizar a los productores del Sur una compensación justa por sus productos y su trabajo.

- Favorecer el desarrollo sustentable, a las minorías étnicas y las culturas y valores locales, en el marco de un diálogo intercultural.

- Concienciar a los consumidores acerca del poder que tienen para actuar a favor de tipos de intercambio más justos.

- Hacer evolucionar las prácticas comerciales hacia la sustentabilidad y la incorporación de los costos sociales y medioambientales, tanto por el ejemplo militante como por un cambio de legislaciones.

- Los productores forman parte de cooperativas u organizaciones y funcionan democráticamente.

- Rechazar la explotación infantil y proteger sus derechos.

- Buscar equidad de género y oportunidades para hombres y mujeres.

- Trabajar con dignidad respetando los derechos humanos.

- El precio que se paga a los productores y sus trabajadores mejora sus condiciones de vida y la de sus familias.

- Valorar la calidad y la producción ecológica.

- Respetar profundamente el medioambiente.

- Evitar intermediarios entre productores y consumidores.

- Informar a los consumidores acerca del origen del producto.

- Si los productores son asalariados, respetar las condiciones de trabajo correspondientes al mínimo de las normas internacionales de la OIT o del país; si estas son superiores a las anteriores, respetar el derecho de asociación y prohibir el trabajo forzado.

- Autorizar un financiamiento parcial antes de la cosecha, si los productores así lo piden.

- Establecer relaciones y contratos a largo plazo, basados en el respeto mutuo y de los valores éticos. Estas relaciones apuntan no solo a establecer un precio justo, sino también a crear las condiciones para un desarrollo sustentable de los grupos de productores o asalariados.

- Incorporar los costos sociales y medioambientales.

- Peso, medida y precio justos para los pequeños productores.

Fuente: http://es.wikipedia.org/wiki/Comercio_justo»; elaborado por el autor. 


\section{Cuadro 2. Resultados exitosos en experiencias de Comercio Justo}

En el Comercio Justo los pequeños productores y campesinos:

- Reciben un trato digno y humano en el trabajo, respetando sus derechos humanos.

- Se capacitan constantemente en diversos temas.

- Alcanzan precios justos por sus productos, acordes con las medidas y una correcta apreciación de la calidad.

- Ellos y sus familias tienen una vida digna.

- Sus hijos asisten a la escuela.

- Están empoderados porque tienen poder en la toma de decisiones, tanto en sus trabajos como en sus comunidades y hogares.

- Existe equidad de género e igualdad de oportunidades para hombres y mujeres.

- Disminuye la violencia intrafamiliar.

- Tienen una buena nutrición.

- Viven en un entorno sano, no contaminan sus tierras ni otros espacios, tienen un profundo respeto por el medioambiente.

- Establecen relaciones y contratos a largo plazo, basados en el respeto mutuo y de los valores éticos.

Fuente: el autor.

\section{Notas}

[1] Por razones de espacio no podemos compartir en estas páginas La Propuesta de Guía Práctica para el Análisis de Experiencias de Comercio Justo. Se la puede conseguir en la investigación mencionada, en la Biblioteca de la UPS o directamente con el autor (yafolo@hotmail.com)

\section{Bibliografía}

CRONIN, David, Desarrollo: El chocolate justo es más sabroso, Agencia de Noticias Inter Press Service, IPS, Bruselas, 23 de abril, 2007.

European Fair Trade Association-EFAT, Anuario 2001, EFAT 2003, tomado de López, Mauricio, Estado del arte del comercio justo en Ecuador, Tesina Flacso- Ecuador, Diplomado Superior en Gestión del Desarrollo Local, Quito, 22 de noviembre, 2005.
MAC MASTER, Bruce, iEs el comercio justo una forma de responsabilidad social?, Revista DINERO, Bogotá, 8 de marzo, 2007.

MARTÍNEZ, Luciano, ¿Puede la pobreza rural ser abordada a partir de lo local?, en ICONOS, Revista de Ciencias Sociales, Año X, No. 29. El mundo rural en los Andes, Flacso, Quito, septiembre, 2007

NIELL, Cristina, En los años 2000-2001 costaba más recoger el café que lo que se obtenía de su venta, Intermón Oxfam, Barcelona, febrero, 2008.

Oxfam internacional, Cambiar las reglas: comercio, globalización y lucha contra la pobreza, Barcelona, 2002.

OXFAM, El café de comercio justo.

VÁSQUEZ, Lola, Ecuador y su realidad, edición 2008-2009, Quito, 2008.

Envío 15 de marzo de 2011 - aprobación 31 de marzo de 2011

Retos I(I): 20II.

(c) 20II, Universidad Politécnica Salesiana del Ecuador 